\title{
ICT POLICY AS A GOVERNABLE DOMAIN: THE CASE OF GREECE AND THE EUROPEAN COMMISSION
}

\author{
Ioanna Chini \\ London School of Economics and Political Science, UK
}

\begin{abstract}
This chapter explores ICT policy as a domain that emerges out of the interplay of national and supra-national efforts. Against this backdrop, the chapter investigates the case study of Greek ICT policy, under the important influences of the European Commission. Foucault's concept of governmentality is constructively used as a theoretical lens to inform the analysis of the empirical data. I argue that ICT policy in Greece has been constituted as a governable domain. An array of techniques which embody the rationale of the Commission's outlook of ICT policy are regulating the conduct of Greek administrators, who, in turn, willingly self-regulate their behaviour in order to keep the relationship going. In effect, the empirical investigation and theoretical analysis of the research presented in this chapter challenge the way ICT policy is traditionally viewed as the product of rational deliberation of a country.
\end{abstract}

Keywords: ICT policy, Greece, European Commission, governmentality

\section{Introduction}

The pervasiveness of information and communication technology (ICT) in society, and the perception that it can form the basis of a national competitive advantage has led to a flurry of national policies geared towards strengthening the society's capacity to adopt and skilfully adapt ICTs. Proactive institutional intervention from governments, be it as part of a neoliberal laissez-faire approach or as part of social welfare discourse, has been a legitimate step to take [26, 27].

The appreciation of ICT as providing a distinct competitive advantage has prompted the involvement of regional and international authorities in joining in the ICT policy field, as the issue was deemed to be too important to allow uncoordinated action or inaction to stifle the economic potential. Therefore, regional authorities, such as the European Union, supranational organisations, such as the OECD, and international organisations, such as ITU and the World Bank, have all stepped forward to create their own ICT visions, backed by policies and programmes of action. The chapter investigates what happens at the intersection of these international demands with national ICT policies. 
National ICT policies have been the focus of academic research for a number of years. Two distinct traditions can be discerned with researchers approaching the topic on the one hand from a localised perspectives, zooming in on a single policy or programme of action, and on the other hand from a bird's eye view, attempting to account for the overall outcomes of year-long interventions. A tendency to understand ICT policy as unambiguous and technical has led to an underestimation of its political nature and implications [3, 22]. A third stream of research, which overcomes this shortcoming, taking a critical approach striving to understand the ideologies embodied in ICT policies, is under-represented, but gaining ground.

The chapter is empirically based on a case study of ICT policy in Greece in relation to the European Union and demonstrates how Greek governments have conceptualised and made ICT policy, while being influenced by the political decisions and programmes of action of the European Commission ${ }^{1}$. The prevalence of contexts worldwide where supra-national organisations play a role in national political decisions begs further investigation, of which this research is an example.

The study explores how the international momentum to create ICT policy is being acted upon in the case of a state which has experienced late modernity [36], has limited technological tradition, and has historically been a late adopter of technological revolutions [47]. The research reveals the vital role the European Commission has played in making available and enforcing the strategic direction, the implementation framework, and the funding. The significant loss of autonomy in this area by Greek state officials was never resisted; the active intervention of the Commission has been welcomed, even as its obtrusiveness has increased through time.

Governmentality is used as the analytical lens through which the analysis of the case is done. The concept was initially developed by Foucault [13, 14], and later by Rose [40] and Dean [6, 7]. The analysis of government is concerned with the techniques that have been used in order to shape conduct so as to achieve certain ends. Tracing the lines of thought, discourses, and programmes of action constitutes its method of enquiry. The concept of governmentality can be more simply understood as a way of exploring how willing subjects are created, that is, subjects whose behaviour is regulated through a series of techniques. The concept is essentially different from simple enforcement or dependency. Agency is required, not negated.

This chapter argues that in the case of Greece the European Commission has rendered the area of ICT policy a governable domain by framing the issues around ICT policy, and utilizing a series of procedures which effectively govern and shape the conduct of Greek policy makers. The state officials in Greece actively engage with the techniques of government and willingly assert their status of subject by acting in ways that please the Commission.

\footnotetext{
${ }^{1}$ From now on the European Commission will be referred to as simply the Commission.
} 
The chapter goes on to review the literature in ICT policy, thus helping to position this piece of work within the existing body of knowledge. The concept of governmentality is discussed and a few elements are extracted to help operationalise it for the purpose of the chapter. In the analysis, key elements of the case study are presented through the lens of governmentality and conclusions are drawn as to the extent to which the concept has helped improve our nuanced understanding of the case.

\section{ICT policy}

ICT policy constitutes a fluid and fragmented area of study, as it has predominantly been of the "adjectival" type [5], focusing on substantive policy issues. Different themes have emerged as important through time: from the development of national competitive advantage through micro-electronics production $[10,11]$, to telecommunications liberalization $[9,29,34]$, national information infrastructures [21, 35], and software outsourcing [4, 12]. The information or knowledge society has been the focus of recent research $[2,30,31$, 46].

The majority of the research takes a localised approach, placing particular policy initiatives at its focus. They provide in-depth, contextual knowledge of the factors that brought a policy to life or of its implementation outcomes [18, 25, 39]. Treating specific policies as independent objects of research, these analyses fail to trace historical interdependencies, and fall short of accounting for the influence of globalised conditions. A further methodological criticism pertains to the difficulty of discerning the impact of a specific policy from all the relevant factors at play [37].

On the other hand, a variety of studies examine the macro effects of ICT policy for developmental goals. Occasionally drawing on an economic rationality, these studies aim at formulating prediction models or at expressing causal relationships [22, 43-45, 48]. In this stream of thought, Iosifidis and Leandros [20] investigate the results of the interventionist policies of the Greek state over the private sector and the civil society in order to foster the creation the information society

Research of this sort allows for a more comprehensive view of the impacts of ICT policy. However, the relatively short time frames examined can lead to overestimation or underestimation of different types of impact, and may not allow for trickle-down effects or spin-offs to be observed [37].

A third significant group in the literature consists of studies that have an ideological approach to ICT policy. The basic premise is that decisions and policies about ICT are rarely the outcome of rational deliberation, but serve instead other ideological purposes. Ideologies become an integral part of policymaking not only because they provide a useful lens through which a new and uncertain situation can be interpreted, but also because they come bundled with acceptable and legitimate courses of action [15, 38]. Studies in this stream usually take as their object of study a policy document or declaration. Their 
intention is to uncover the hidden ideological assumptions that are embedded in the policy discourse and which shape the form and goals of policy itself.

Such research has examined ICT policies of national governments [8, 17, 24, 42]. The European Union's rhetoric on the information society has been ideologically critiqued as upholding the economic aspects at the detriment of social and cultural considerations [16, 19].

This tradition has produced a number of intriguing studies. A shortfall of this type of research is that studying policy declarations does not equate with studying ICT policy. Ideologies do not exist in a vacuum, nor do they diffuse without active human intervention. Instead, they form part of a material arrangement which sustains them and allows them to have real-world effects. Thus, it makes much sense to open the focus from the ideological study of policy documents to the material arrangements that bring them to life [15, 23].

The existing research on ICT policy has not looked into the phenomenon of ICT policy being led by external, usually supranational, organisations which communicate the visions about the information society and control significant sources of funding. Exploring such a situation can bring forward different interpretations of the reasons why ICT policy is pursued, the conditions under which this is done, and the effects is has on the socio-economic fabric of society. This is where this research contributes.

\section{Governmentality}

The concept of governmentality appears in Foucault's later lectures and writings as a way to move forward with the question of knowledge and power and to explore the domain of government as the "conduct of conduct" [13, p.220]. The idea of governmentality tries to bring to light the collective, taken for granted, thought involved in practices of government, which is rarely challenged [14]. The prevalent question "who is governing" becomes "how the governing of ourselves and others happen".

This question can be answered by pursuing an analytics of government [7, 40]. The goal is to understand the underlying rationale hidden in the complex nexus of institutional relationships and programmes of action. Instead discussing of ideology, the analytics of government is concerned with thought as it is embedded in material arrangements and technical means of shaping conduct. Foucault uses the term regimes of practice to denote the complex assemblage of institutions, programmes of action, techniques and technologies through which truth is produced.

Foucault is thus exploring a process of subjectification: the way in which agents are constituted as subjects and are brought to willingly conduct themselves accordingly. The strength of the concept lies in its emphasis on how conduct is shaped in the different locales and how individuals create themselves as subjects and locally produce truth through the regimes of practice at play. In this way, governmentality does not negate agency; to the contrary, it requires agency so as 
to allow for the individual to act and either reinforce or challenge the regime of practice.

Providing a more flexible interpretation of government and power, as well as a way to investigate the material and technical arrangements in which mentalities of government are embedded, the concept of governmentality appears to be a fruitful lens for looking into a regulated domain such as the domain of ICT policy in Greece. It is possible to move away from the question of "who governs" and proceed to discuss how governing is taking place and how all parties involved regulate their conduct according to the desired ends, the telos of the government.

Methodologically, the analysis of government is concerned with "how" questions. The emphasis is on deciphering how conduct in specific domains is regulated by studying the technical means in which such regulation is inscribed in order to be effective.

Dean $[6,7]$ argues that when pursuing an analysis of government the regimes of practice can be analysed along four closely intertwined, but relatively autonomous, dimensions. Firstly, forms of visibility render certain aspects of government visible, while others remain obscure and unchallenged. The visual dimension of government, expressed through charts, diagrams, images and tables, helps define what or who is to be governed, assigns roles, and constitutes identities. Secondly, regimes of practice can be analysed in terms of the technical aspects of government, i.e., the procedures, instruments, techniques, vocabularies, and technologies by which government is accomplished. This corresponds to the techne of government and is congruent with the emphasis on how thought operates by being embedded in real-world arrangements. The third dimension looks into the question of thought and is aiming to establish the kinds of knowledge claims that are being upheld as valid. In effect, this is a quest to understand the rationality of government. Finally, the fourth element concerns the formation of identities for those that govern and those that are being governed. What capacities and attributes are they invested with and how are they to comport themselves?

This chapter will focus on the second of these elements, the technical means of government. It will discuss the different means used to constitute the field of ICT policy as a governable domain, and will attempt to demonstrate the types of technical and material means on which government has been inscribed. In this quest, the boundaries between techniques, identities, forms of visibility, and the telos of government will inevitably be blurred; however, for reasons of size restrictions, these will not be the focus of this chapter.

\section{Methodology}

\subsection{Data collection}

Data for the study was drawn from two domains. Firstly, twelve semistructured interviews were conducted with policy makers in the European Commission. These included people from various departments, such as the Fund 
for Regional Development, the Social Fund, the Directorate-General for Enterprise and Industry, and the Directorate-General for the Information Society. A common denominator for all the interviewees was that they were, either at the time of the interview or in the past, involved in making ICT policy inside the Commission. They were also all involved in negotiations with the Greek side in order to monitor or help in the implementation of the policies.

Secondly, forty semi-structured interviews were conducted in Greece with stakeholders involved in different areas of ICT policy, including past and present state officials working on ICT policy from the formulation to its implementation, past and present civil servants, consultants and IT implementers, involved in cofinanced IS projects, public procurement managers in IT companies, and trade union representatives and public procurement managers in IT companies.

Because the domain of ICT policy was particularly fragmented, different groups of informants were aware of only some of its facets. As such, the themes to be discussed in the interviews were determined after carefully considering the experiences and position of each informant within the field. The overarching themes that transcended the field study pertained to understanding how individuals made enough sense of the technological innovations around them to create a developmental vision, how they reached decisions about the types of actions to be pursued, how they managed the relationship with the European Union, and how they understood the outcomes of their efforts. The informants were encouraged to explain their concerns and aspirations, their day-to-day realities, and their opinions. The researcher compiled a storyline of events on which the majority of accounts converged and thereafter treated the opinions as part of the informants' identities and assessed them accordingly.

Alongside the interviews, written material was gathered and analysed. The websites of the Commission and the Greek information society office were scrutinised, as they contained vast amounts of information on their activities, highlighting their concerns at different points in time. Apart from the widely available information, the researcher was lucky enough to be offered some access to the informants' private archives, thus gaining access to material often forgotten. The field study resulted in the collection of three hundred pages of personal notes and more than a thousand pages of printed material.

\subsection{Data analysis}

The study is a case study dealing with a contemporary phenomenon [49]. The phenomenon appears, however, to be particularly defined by path-dependent processes, and so a historical perspective was deemed necessary to allow us to understand the structural elements of the case. The work of Mason, McKenney et al. [32] guided the collection and analysis of the data. Analysing the data consisted of determining patterns, trying out causal chain scenarios, and establishing empathy with the protagonists of the story [32]. The researcher's impressions were compiled in an analytical narrative [33], which highlighted 
important and recurrent themes, as well as temporal and causal linkages. The analytical narrative recounted the policies designed and implemented on ICT for almost two decades, 1985-2006, tracking in parallel the history of Greek and European ICT policy. For the purposes of the chapter, only data from the later stage, 1999-2006, is considered.

\section{Case study}

\section{$5.1 \quad$ Case background}

Greece joined the European Community in 1981, but has neither managed to reach levels of economic growth and development similar to those of other EU members nor to achieve full integration. Located in the geographical periphery of the EU, Greece also has remained peripheral socio-economically [47]. Greece has, however, been particularly influenced by the EU, by both its "hard" policy measures, such as regulations, and its "soft" approaches, such as targets and benchmarks, developmental plans and financial incentives [41,50]. Greece is a net beneficiary of Community funding [28]; financial assistance has been received since 1987 in various areas, among which ICT.

A Community Support Framework (CSF) is an EU instrument which groups all the funding to be made available to a member-state in a given time frame, so that the goals of cohesion and integration can be pursued. Operationally, CSFs are broken down in smaller sub-programmes which are sector- or theme-specific (e.g., shipping or human capital creation). The negotiation of a CSF determines the domains where funding is to be channelled, the types of interventions to be pursued, the overall rationale of the intended intervention, the criteria of evaluation, as well as the budgets. In the timeframe of six years the funds need to be funnelled into specific projects, while the projects need to be finished two years after the end of the CSF. For each CSF, a management and monitoring mechanism is set up in the member-state in order to evaluate the progress of the CSF on an annual basis.

Greece has been making policy decisions on ICT for the past two decades. ICT policy and ICT investment has revolved around the funds made available from the European Commission. Horizontal, ICT-specific programmes of action were negotiated with the Commission as sub-programmes under the CFSs, and implemented nationally. These IT-specific operational programmes, initiated in 1987, proved to be the driving force behind any orchestrated governmental effort regarding ICT.

To briefly summarise what has happened before 1999, the first CSF was initiated in 1987, the second in 1993, and the third in 2000. In each one, there was provision and funding to carry out developmental IT interventions, although the criteria for what was considered developmental shifted with time. In CSF1, large data centres were created for key areas of the public administration. In CSF2, the creation of physical and informational infrastructures was funded. In CSF3, the 
priorities were the liberalisation of the telecommunications, and the use of the Internet, particularly in e-government services. The Commission was jointly involved in the monitoring and operational management of the programmes up until the end of the CSF2, effectively co-determining their course. It relinquished its operational monitoring role in favour of a more executive one from the CSF3 onwards.

\subsection{Narrative}

Around the turn of the century, the theme of the information society gained increasing visibility. In 1999, a group of eight advisors, public servants and academics, led by the prime minister's Advisor for the Information Society, created the White Bible for Greece's entry into the information society. This nonbinding policy paper documented its authors' vision for the role of ICT in the country's progress.

Concurrently, the country's administration was negotiating with the Commission the formulation of CSF3, which would be co-financed to a large extent by the Commission. Successfully negotiating and signing the CSF3, and maximizing the amount of funding were key political targets for the government. With the global rise to prominence of the issue of the information society, a subprogramme focusing on institutional intervention for the adoption of ICT was also being negotiated by the PM's Advisor to the Information Society. The White Bible was the wild card used in the negotiations to demonstrate the country's proactive and strategic planning for the information society.

CSF3 was signed in the spring of 2000, and the sub-programme for the information society, called OPIS (Operational Programme Information Society), was one of the first sub-programmes to be agreed upon and signed. It included the provision of a 3 billion fund to be funnelled into projects of information systems and IT-enabled change by the end of 2006. The projects had to be selected on the basis of specific criteria, and were to be incorporated in one of four categories: education and culture, public services to citizens, assistance to businesses, and telecommunications.

The majority or the available funds was committed towards providing online services to citizens, i.e., in projects of e-government. All authorities were urged to put forward proposals for projects which were visibly outwards-facing, linking the administration to the citizens. Projects of back-office computerization were not deemed congruent with the spirit and the criteria of the programme. Citizen orientation was the key criterion to be fulfilled.

A complex organisational structure was implemented to carry out the programme, involving a funds managing authority, a project management and implementation authority, and an observatory. The funds managing authority was responsible for the selection, monitoring, and evaluation of the projects. The implementation authority was responsible for assisting with project management when the organisations were not deemed to have the capacity to run their projects. 
Finally, the observatory would gather data to influence policy and to report to the Commission to enable benchmarking.

During the course of the 6-year period of the programme a number of further attempts were made to create new ICT strategies. In 2003, a new strategy was drafted, introducing a set of different priorities from the White Bible. A final version was never created as the national elections of 2004 brought a different party in power. OPIS came to an overhaul, as the leadership changed completely. In 2005, the new leadership which had been in office for less than a year initiated the creation of, yet again, a new strategy called the Digital Strategy.

As the Digital Strategy was being created, the EU called on member-states to articulate how they planned to pursue the targets of the Lisbon Strategy, which was agreed in 2000 with the strategic vision to make Europe a competitive knowledge-based society. Member-states had to express their plans in a National Strategic Reference Framework (NSRF), which would be negotiated with the Commission. The NSRF would form the basis of further negotiation for funding for the subsequent period 2007-20013. As had happened six years before, the newly written Digital Strategy formed an integral part of the Greek NSRF and secured a new co-financed programme for ICT.

\section{Analysis}

The storyline has indicated the existence of a co-constructive relationship between Greece and the Commission in creating the Greek ICT policy. I argue that the domain of ICT policy has been constituted as a governable field, where the Commission heavily influences the conduct, the decisions, and the policies of Greek policy makers. In the next section, different facets of this relationship are explored, in order to demonstrate not only its existence, as it manifests itself through technical means, but also the extent of its pervasive outcomes.

\subsection{Procedures in regimes of practice}

A number of procedures which came as part and parcel of OPIS constituted powerful elements in the regime of practice and through their operation effectively shaped the conduct of Greek policy makers and implementers.

\subsubsection{Complying with the aims}

As suggested above, the Commission had clear development targets, which it was trying to achieve through member-states. Although it could not straightforwardly dictate the directions to be followed, as in areas of telecommunications policy, it managed to effectively do just that through the negotiation process of the CSFs. Although all CSFs had a clear mandate, which matched the strategic priorities of the EU and the vaguely expressed developmental goals of Greece, CSFs 1 and 2 had lax enough procedures to allow 
individual decisions to be made nationally, even when they contradicted the official mandate.

CSF3was, however, a much more tightly coupled programme, and when it came to ICT, OPIS embodied the then preoccupation of the Commission with egovernment. E-government had gained much credibility in the Commission for a number of reasons. Firstly, e-government could prove to be an effective means of European intervention within the national public administrations, for which the Commission could find little support in the treaties. It was envisaged that egovernment could be the catalyst of public sector reform, which would, through the creation of interoperable systems, allow the tighter coupling of public administration across Europe. Also, e-government was a technological solution to the crisis of transparency and accountability that had struck the Commission [1]. For all these reasons, the Commission placed e-government high in its informal list of priorities. It insisted, though, that any funding under OPIS be channelled to projects of services to citizens. OPIS was negotiated and agreed with this outlook, and it thus became the instrument in which the specific ideas of the Commission about what was considered legitimate technological intervention to achieve a particular type of development were inscribed.

\subsubsection{Procedures of acceptance}

Another set of procedures and devices that defined the regime of practice was the array of procedures of acceptance of projects that were deemed suitable for funding. This role was entrusted to the staff of the funds managing authority who were accountable to the Commission and the Greek state if funds were committed to projects which were later found unsuitable or incongruent with the criteria.

Three distinct devices can be identified. Firstly, the acceptance criteria which had been set and agreed with the Commission framed the types of eligible projects. Projects needed to have an obvious orientation towards the "citizenmade-customer" if they were taking place in the context of the public administration (which was more often than not the case). If projects were in the telecommunications sector they needed to strengthen competition and not favour the incumbent.

The obvious result of the above and other acceptance criteria on the ground was that they defined the way in which projects were described and represented when submitted for approval. As a result, innumerable projects titled "Project for the creation of Web portal for the provision of electronic services to the inhabitants of [...]" were submitted and approved. Consulting companies also swiftly changed their product line to offer products that would allow their clients to obtain approval. The acceptance criteria shaped the conduct of a wide array of stakeholders, who were willing to change their expectations and desires to fit with what was being put forward as legitimate, and in so doing irreversibly defined the direction of information systems diffusion.

Two further devices are also interesting: the development goals and the maturity tables. The former was meant to measure the potential of a project to spur 
socio-economic development, for example by counting the number of employment opportunities to be created. The latter was meant to assess the capability of the organisation to undertake the project, by having experience in similar projects or by having experts in the project management team. If they were not deemed to be "mature" enough to manage the project themselves, the project could only be approved if the project management was outsourced to professionals.

Both of these devices were particularly resisted and distorted in practice, in essence making them just another formality void of content. The development goals reflected the preoccupation of the Commission with the creation of employment for skilled work, as it was expressed in the Lisbon Strategy in 2000. In practice, the number given often reflected the number of temp cleaning staff that would be laid off and re-employed in the specified time frame. To get over the maturity tables, expert academics would often be included in the project management team for a nominal fee, and would later leave the team.

\subsubsection{Procedures of financial administration}

Perhaps the most important form of regulation of the conduct which had the greatest impact on the character of the results was the procedures of financial administration. These related to monitoring of the progress of IS projects and reporting both internally and to the Commission. These procedures had been put in place by the Commission to prevent the mismanagement of funds, something that had happened in previous CFSs. These procedures of financial management fundamentally shaped the conduct of all involved and meant that the economic rationality prevailed over other competing rationalities.

An invention that demonstrates the above point was the separation of an IS project in two parts: the "financial object" and the "technical object". The financial object included the budget and the expenses of a project. The technical object was comprised of the actual information system of the IS-mediated intervention. The financial object overshadowed the technical object in formal and informal discussions, in the controls and assessments, and in the monitoring of individual projects and of the whole OPIS programme. From the speeches of public figures to the informal chats in the corridors of the OPIS building, discussions revolved around the amount of money spent, or committed to be spent. The level of expenses of a project was used as a proxy for judging its progress. The information system which was used as the main monitoring tool for the progress of the programme, named Ergosys, could record financial information, but could not keep track of information regarding actual deliverables or products. The staff often improvised their own database applications to allow them to track the progress of the information system itself.

One of the most destructive effects of the supremacy of the financial object over the technical object was that it created two incompatible goals for all those involved in the process. They could either try to deliver according to the financial object, i.e., do the bare minimum that would allow them to claim back the expensed from the Commission, or they could try to uphold the importance of the 
technical object, i.e., the need to implement information systems that make a difference. The second goal was sidestepped in favour of the first, and so spending money in accordance with the Commission's regulations became more important than making a difference with IT. The developmental goal was lost.

The preoccupation with the financial administration was liked to a high-level discourse on absorption rates, i.e., how much of the available funds were funnelled to projects at any time, an amount that was being reported by the Commission at regular intervals. The discourse on absorption of funds was made material in a multiplicity of rules, procedures, instruments, and technologies. The motoring reports were filled in for all projects monthly, quarterly, and annually by the projects' beneficiaries and IT contractors, detailing all expenses for all projects. The reports were uploaded in Ergosys and became the object of scrutiny by the Greek management of OPIS and the Commission. Administrators in both sides (Greece and the Commission) lamented having become "accountants". The evaluation targets of all stakeholders involved in the implementation were expressed not in terms of number of projects finished but of volume of funds absorbed. The chart showing the expenses in juxtaposition to the available budget was published every month on the website, and was occasionally the issue of public outcry, when the Greek media discovered that "Greece is losing money", not that Greece is failing to make useful interventions with IT.

Overall, financial administration was the major way of regulation of conduct in the Greek efforts to do ICT policy. The vocabulary of funds absorption was set by the Commission and embraced, with some complaining but with no serious objections, by the Greek administration. Even though they could have resisted the imposition of the economic rationality, in the same way that they resisted the maturity tables, they willingly took up the discourse and reified it, by, for example, reproducing it through the media or in the political scene. These processes of financial administration also formed the identities of the people involved: they were administrators that tried to make the numbers work, instead of trying to make the interventions work. They were "accountants".

\subsection{The "IT strategy" as an example of self-regulation}

Having seen a number of examples where conduct was regulated by providing clear directions, it is important to show an example where conduct was selfregulated based on what the agents felt they were expected to do. For this, I demonstrate how the instrument of the "IT strategy" was used by Greek policy makers.

The narrative of the case study points to the creation of three Greek IT strategies in the course of six years. Two of them were created just before the negotiation of CSFs, in 1999 and 2005. One of them was created in 2003 half-way through the programme. These temporal coincidences and the interview responses of the creators of these strategies highlight the reasons why their creation was felt imperative. The White Bible in 1999 was meant to show to the Commission that 
Greece was a trustworthy partner with a well considered plan about what to do with IT. The IT strategy was thought to make right the very poor results of the IT programmes in CSF2. Without proof of commitment the Greek policy makers thought that the Commission would not agree to an ICT programme in CSF3.

The reasons that were hinted at for the creation of a new IT strategy in 2003 were similar. Programme OPIS had got off to a slow start with very low absorption rates which sparked fierce criticism from the Commission in the annual Monitoring Committees. A new strategy was meant to reassure the Commission that, despite the problems in implementation, there was still determination to do ICT policy.

In 2005, nearing the completion of programme OPIS and the negotiation of CSF4, yet another strategy was created. The new leadership reluctantly expressed their certainty that had it not been for their strategy the Commission would not have approved another ICT programme under the CSF4.

This constitutes a striking example of self-regulation of conduct. The Greek administrators and policy makers acted in ways that they believed were congruent with what the Commission expected from them. They willingly governed and shaped their conduct according to what they thought were the appropriate ways to keep the Commission satisfied. The self-governing of conduct could signify that the regime of practice was potent enough to make them behave in certain ways, even in aspects of their conduct where they did not experience the direct influence of techniques of government.

\section{Discussion}

ICT policy in Greece has, in effect, been a product of the relationship between Greek authorities and the European Commission. The way this relationship unfolded and manifested itself, as well as its results, have largely remained obscure. This chapter argued that viewing the phenomenon through the analytical lens of governmentality would bring to light interesting facets which would allow us to develop a more nuanced understanding.

In analysing the case study evidence was provided to support the contention that ICT policy has been defined as a governable domain. By looking into the technical means in which governing is embedded and which make governing material and durable, a wide range of procedures which constituted a regime of practice were discussed. It was showed how the acceptance criteria defined the legitimate IT interventions to be pursued, while making a whole array of stakeholders regulate their conduct so as to fit with the specified requirements. On the other hand, some devices were demonstrably covertly resisted and subverted in their everyday enactment, thus pointing to the fact that not all attempts to regulate conduct are successful all the time.

The analysis has shown that procedures of financial administration, along with an array of technological artifacts and associated discourses, were particularly successful in not only shaping conduct, but also creating identities and framing the 
issue. An array of procedures about the financial management of the information society was developed to closely regulate the conduct of the disobedient Greek administration who had in the past distorted the efforts and intentions of the Commission. Although financial mismanagement was still occurring, the regime of practice was extremely successful in making the information society a question of budgets and expenses instead of IT interventions. The discourse on funds absorption, although initiated by the Commission, was avidly taken up by all involved and was reproduced in the media and the politics, effectively showing the only legitimate way to discuss technological progress.

On the other hand, taking the creation of IT strategy as an example, the Greek administration was shown to self-regulate its conduct by acting in the ways they felt responded best to the Commission's expectations. The IT strategy was not a response to a rational need. The rationality behind its creation was not formal rationality. Instrumentality was part of the response and there are questions to be asked as to the extent to which the self-regulation of conduct was merely a superficial external manifestation of a desirable behaviour, or whether it had indeed formed an identity which participants shared and acted accordingly. Such questions are not, however, pertinent to understanding how ICT policy got constructed and acted upon in the specific context and under the influence of particular institutional relations.

Finally, rounding up the discussion, I would like to suggest that the concept of governmentality and its related concept of regimes of practice provide a particularly fruitful analytical lens in dealing with situations of multilevel relations. Because they assume power in all relations, power becomes an enabler instead of a sterile fight over resources. Thus, they can inform much more subtle and nuanced analytical accounts. An important challenge that has to be addressed, however, is the difficulty in operationalising concepts which Foucault has defined loosely and used imaginatively.

\section{Conclusion}

In this chapter I have attempted to examine the example of ICT policy in the case of Greece under the influence of the Commission with the help of Foucault's ideas on governmentality $[13,14]$. The aim has been to better understand the phenomenon of creation of ICT policy as it emerges out of the interplay of two levels of government. The motivation for this research has been the multiplicity of cases where ICT policy is not solely the product of national deliberation, but the emergent product of a process where the European Commission (or similar international bodies) is promoting a strategic vision and also makes available the funding for its implementation.

The existing literature remains silent about the phenomenon of institutional intervention from regional and supranational organisations in the national interpretations and policies on ICT. Although some research, mainly from the critical tradition, have challenged the neutrality of the European Union's ICT 
policies $[15,16,19,38]$, similar critiques have not been applied to national ICT policies. On the contrary, these are viewed largely uncritically, although such research has produced a wealth of information about individual approaches to national ICT policy [22, 43-45, 48].

I have argued for an alternative approach in understanding ICT policy as a governable space, where the rationale of the Commission's vision of the information society is embodied in material practices which regulate the behaviour of Greek administrators. Simultaneously, administrators in the national level also self-regulate their conduct in ways that are thought to be compatible with what they feel is expected of them, also making use of technical means of government. The contribution of the chapter is twofold. On the one hand, it uses a novel theoretical approach in examining ICT policy to come up with a more subtle discussion of the situation. The lens of governmentality has enriched the analysis of the phenomenon, allowing for nuanced observations of the social agents and their institutional environments to be drawn. It thus provides an interesting alternative to theories of power and coercion, particularly as the relational, diffused character of power allows attention to be placed on the material (and technological) arrangements that structure social contexts. On the other hand, the chapter contributes through its empirical investigation in the reframing of an area of study. The findings shed light into an aspect of ICT policy that has received very little attention, namely the interplay of two different levels of governance of ICT policy.

Further research needs to investigate the other three dimensions of the regimes of practice, i.e., the rationalities of government, the forms of visibility and the formation of identities. Although some links were drawn here, a more thorough exploration could yield interesting insights. Also, further research could be directed towards investigating whether the results of the study are supported in other contexts which look similar to this one, for example in contexts of the development agencies and international donors in relation to developing countries.

\section{Acknowledgements}

Funding for this research was provided by the Propondis Foundation, in Greece. I am deeply grateful for their continuing support, without which the research would not have taken place.

\section{References}

[1] Alabau, A. (2005). The European Union and its eGovernment development policy: Following the Lisbon strategy objectives. Madrid: Ed. Fundacion Vodafone.

[2] Berleur, J., Galand, J.-M. (2005). ICT policies of the European Union: From an information society to eEurope. Trends and visions, in J. Berleur and C. Avgerou (Eds.) Perspectives and policies on ICT in society: An IFIP TC9 (Computers and Society) handbook, New York: Springer. 
[3] Bijker, W.E. (2001). Understanding technological culture through a contructivist view of science, technology, and society, in S. Cutcliffe and C. Mitcham (Eds.) Visions of STS: Counterpoints in science, technology and society studies (pp. 19-34), Albany: State University of New York Press.

[4] Carmel, E. (2003). The globalization of software outsourcing to dozens of nations: A preliminary analysis of the emergence of the 3rd and 4th tier software exporting nations, in S. Krishna and S. Madon (Eds.), The digital challenge, Ashgate: Aldershot.

[5] Colebatch, H.K. (2002). Policy. 2nd ed., Maidenhead: Open University Press.

[6] Dean, M. (1996). Putting the technological into government. History of the human sciences, 9(3), 47-68.

[7] Dean, M. (1999). Governmentality. London: Sage Publications.

[8] Diso, L.I. (2005). Information technology policy formulation in Nigeria: Answers without questions. The International Information \& Library Review, 37(4), 295-302.

[9] Dutton, W. (1992). The ecology of games shaping telecommunications policy. Communications Theory, 2(4), 303-328.

[10] English, M. \& Brown, A.W. (1984). National policies in information technology: Challenge and responses. Oxford Surveys in Information Technology, 13(1), 125-142.

[11] Evans, P.B. (1992). Indian informatics in the 1980s: The changing character of state involvement. World development, 20(1), 1-18.

[12] Forbes, N. \& Wield, D. (2002). The Indian software industry: Miracle in the making or a high-technology "sweet-shop"?, in N. Forbes and D. Wield (Eds.) From followers to leaders, London: Routledge.

[13] Foucault, M., (1982). The subject and power, in H. Dreyfus and P. Rabinow (Eds.) Michel Foucault: Beyond structuralism and hermeneutics, Brighton: Harvester.

[14] Foucault, M. (2007). Security, territory, population. Lectures at the College de France 1977-1978. Basingstoke: Macmillan.

[15] Galperin, H. (2004). Beyond interests, ideas and technology: An institutional approach to communication and information policy. Information society, 20(3), 159168.

[16] Garnham, N. (1997). Europe and the global information society: The history of a troubled relationship. Telematics and informatics, 14(4): p. 323-327.

[17] Garnham, N. (2000). 'Information society' as theory and ideology: A critical perspective on technology, education and employment in the information age. Information, communication \& society, 3(2), 130-152.

[18] Gil-Garcia, J.R. (2004). Information technology policies and standards: A comparative review of the states. Journal of Government Information, 30(5/6), 548560.

[19] Goodwin, I. \& Spittle, S. (2002). The European Union and the information society: Discourse, power and policy. New media \& society, 4(2), 225-249.

[20] Iosifidis, P. \& Leandros, N. (2003). Information society strategies in the European context: The case of Greece. Southeast European and Black Sea studies, 3(2).

[21] Kahin, B. \& Wilson, E. (Eds.) (1997). National information infrastructure initiatives: Vision and policy design. MIT Press: Cambridge \& Massachusetts.

[22] King, J.L., et al. (1994). Institutional factors in information technology innovation. Information systems research, 5(2), 139-169.

[23] Kumar, K. (2005). From post-industrial to post-modern society. Oxford: Blackwell Publishing.

[24] Kuppusamy, M. \& Santhapparaj, S. (2005). Investment in information and communication technologies (ICT) and its payoff in Malaysia. Perspectives on global development and technology, 4(2), 147-167. 
[25] La Rovere, R.L. (1998). Diffusion of information technologies and changes in the telecommunications sector: The case of Brazilian small- and medium-sized enterprises. Information technology \& people, 11(3), 194-206.

[26] Land, F. (1983). Inaugural lecture. Information technology: The Alvey report and government strategy, London: London School of Economics and Political Science.

[27] Land, F. (1990). Viewpoint: The government role in relation to information technology. International Journal of Information Management, 10, 5-13.

[28] Majone, J.M. (2003). The politics of southern Europe: Integration into the European Union. Westport: Praeger Publishers.

[29] Mansell, R. (1993). The new telecommunications: a political economy of network evolution. London: Sage.

[30] Mansell, R. \& Streinmueller, E. (2000). Mobilizing the information society strategies for growth and opportunity. New York: Oxford University Press.

[31] Mansell, R. \& Wehn, U. (1998). Knowledge societies: Information technology for sustainable development. Oxford: Oxford University Press.

[32] ason, R., McKenney, J., \& Copeland, D. (1997). An historical method for MIS research: Steps and assumptions. MIS Quarterly, 21(3): p. 307-320.

[33] ayntz, R. (2004). Mechanisms in the analysis of social macro-phenomena. Philosophy of the social sciences, 34(2), p. 237-259.

[34] Mosco, V. (1988). International Telecommunication What Price Policy? Toward a Theory of the State and Telecommunications Policy. Journal of Communication, $38(1), 107-124$.

[35] Mosco, V. (1998). Myth-ing links: Power and community on the information highway. Information Society, 14(1): p. 57-62.

[36] Mouzelis, N. (1995). Modernity, late development and civil society, in J.A. Hall (Ed.) Civil society, (pp. 224-249), Cambridge: Polity Press.

[37] Mueller, M. \& Lentz, B. (2004). Revitalizing communication and information policy research. The Information Society, 20(3): p. 155-157.

[38] North, D.C. (1990). Institutions, institutional change and economic performance. New York: Cambridge University Press.

[39] Qureshi, S. (2005). E-government and IT policy: Choices for government outreach and policy making. Information technology for development, 11(2), 101-103.

[40] Rose, N. (1999). Powers of freedom. Cambridge: Cambridge University Press.

[41] Schlesinger, P. (1999). Changing spaces of political communication: The case of the European Union. Political communication, 16: p. 263-279.

[42] Selwyn, N. (2002). E-stablishing and inclusive society? Technology, social exclusion and UK government policy making. Journal of Social Policy, 31(1), 1-20.

[43] Shih, E., Kraemer, K.L. \& Dedrick, J. (2007). Research note: Determinants of country-level investment in information technology. Management science, 53(3), 521-528.

[44] Shih, E., Kraemer, K.L., \& J. Dedrick, (2008). IT diffusion in developing countries. Communications of the ACM, 51(2): p. 43-48.

[45] Silva, L. \& Figueroa, E. (2002). Institutional intervention and the expansion of ICTs in Latin America: The case of Chile. Information, Technology and People, 15(1), 825.

[46] Steinmueller, W.E. (2002). Knowledge-based economies and information and communication technologies. International Social Science Journal, 54(171), 141-153.

[47] Thomadakis, S.B. (1995). The Greek economy and European integration: Prospects and threats of underdevelopment, in D. Constas and T.C. Stravrou (Eds.) Greece prepares for the twenty-first century, Washington: Woodrow Wilson Center Press. 


\section{Social Dimensions of ICT Policy}

[48] Tigre, P.B. J, B.A. (2001). Brazil meets the global challenge: IT policy in a postliberalization environment. The Information Society, 17(2), 91-103.

[49] Walsham, G. (1995). Interpretive case studies in IS research: Nature and method. European Journal of Information Systems, 4(2) 74-81.

[50] Wincott, D. (2003). Beyond social regulation? New instruments and/or a new agenda for social policy at Lisbon? Public administration, 81(3), 533-553. 